\title{
ANEURYSM PULSATILITY AFTER ENDOVASCULAR EXCLUSION - AN EXPERIMENTAL STUDY USING HUMAN AORTIC ANEURYSMS
}

\author{
Hussein Amin Orra ${ }^{a}$, Pedro Puech-Leão ${ }^{a}$, Erasmo Simão da Silva ${ }^{a}$, Domingos \\ Guerino Silva ${ }^{b}$
}

Orra HA, Puech-Leão P, da Silva ES, Silva DG. Aneurysm pulsatility after endovascular exclusion - an experimental study using human aortic aneurysms. Clinics. 2008;63(1):67-70.

OBJECTIVE: To measure the pulsatility of human aneurysms before and after complete exclusion with an endograft.

METHOD: Five aortic aneurysms obtained during necropsy were submitted to pulsatile perfusion before and after implantation of a bifurcated endograft. The specimens were contained in a closed chamber filled with saline solution. A vertical tube attached to the chamber was used to measure volume dislocation in each systole. Mural thrombus was kept intact, and the space around the device was filled with human blood. After each experiment, the aneurysm was opened to check for the correct positioning and attachment of the device.

RESULTS: The level of the saline column oscillated during pulsation in each case, with respective amplitudes of 17, 16, 13, 7, and $25 \mathrm{~cm}$ before the endograft insertion. After the insertion, the amplitudes dropped to 13, 12, 9, 3.5, and $23 \mathrm{~cm}$, respectively. The differences were not significant. During the post-experimental examination, all devices were found to be in position and well attached to the neck and iliacs. No endoleak was detected during perfusion or by visual inspection.

CONCLUSION: Pulsation of an endograft is transmitted to the aneurysm wall even in the absence of endoleak, and should not be interpreted as procedural failure.

KEYWORDS: Aorta, abdominal. Aortic neurysm, abdominal. Endoluminal repair. Pulsatile flow. Vascular surgery.

Endovascular aneurysm repair (EVAR) aims to prevent expansion and rupture, by completely excluding blood flow from contact with the aneurysm wall. Radiological demonstration of a type I or III endoleak is always taken as a failure of the procedure; however, several recent reports have shown that aneurysm enlargement can occur without demonstrated endoleak, ${ }^{1,2}$ leading to a search for non-radiological predictors of late failure ${ }^{3}$. Some of these are sac pressurization (endotension), pulsatile wall motion, and aneurysm sac pulsatility.

\footnotetext{
a Cirurgia Vascular e Endovascular, Faculdade de Medicina da Universidade de São Paulo - São Paulo/SP, Brazil.

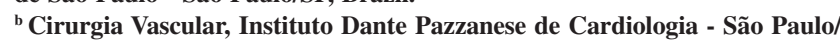
SP, Brazil.

drpuech@usp.br

Received for publication on August 28, 2007.

Accepted for publication on September 19, 2007.
}

Endotension is defined as continued sac pressurization without endoleak, after extensive investigation proving that endoleak is not present. ${ }^{4,5}$ Pressure might be transmitted through the walls of the endograft, through pulsatile movements of the graft wall, through a thrombus lining the attachment site or through a thrombus sealing an endoleak.

Pulsatile wall motion (PWM) is an ultrasonographic concept that reflects the intraluminal systolic-diastolic pressure flutuations. ${ }^{6}$ PWM correlates with aneurismal pulse pressure (the difference between systolic and diastolic pressure), but not with mean pressure. ${ }^{7,8}$

Aneurysm sac pulsatility (ASP) is a clinical definition based on an expected reduction in aneurysm movement after EVAR. ${ }^{8}$ Pulsatility may be the result of sac pressurization, but not in all cases. Theoretically, a situation in which the pressure is high but constant results in no pulsatility. 
Conversely, low pressures with wide systolic-diastolic variation may cause wide pulsatility. ${ }^{6,7,8}$

The importance of aneurysm pulsation after EVAR is still not clear. Some believe that it represents incomplete exclusion of the aneurysm, ${ }^{9}$ while others accept it as independent of endoleak or endotension. During a conference of experts in the field held in the year 2000, the following question was posed: "If an abdominal aortic aneurysm is pulsatile after endovascular abdominal aortic aneurysm repair, it is evidence of an endoleak?" Fifteen of the 26 respondents disagreed, nine agreed, and two were uncertain. ${ }^{10}$

Although there has been intense research in this field, based mainly in animal models or prosthetic aneurysms, there is a lack of important biomechanical analysis related to human aneurysm tissue and hemodynamic flow. This experimental study was designed to measure the pulsatility of human aneurysms before and after complete exclusion by EVAR, and was approved by the Institutional Ethics and Research Committee.

\section{METHOD}

Five infrarenal aortic aneurysms were obtained during human necropsies one to three hours post-mortem. None of them were ruptured nor were they the cause of death. The dimensions of each aneurysm are shown in Table 1.

A complete arterial segment, comprising the aorta from the renal arteries to the external iliacs, was harvested and dissected. The stumps of all branches were ligated and the aneurysms were not opened, thus preserving the intact mural thrombus. The specimens were conserved at temperatures lower than $-4{ }^{\circ} \mathrm{C}$ until the date of the experiment, a period that ranged from one to seven days. Prior to the experiment, the specimens were thawed to room temperature and used as soon as the process of thawing was completed.

The pulsatility of the aneurysms was measured using a flow simulator. This consists of a pump which promotes pulsatile flow with controlled pressures and frequency. These parameters were set at $120 \mathrm{X} 60 \mathrm{mmHg}$ and 80 pulses/minute, respectively. The specimens were tied to the pump at the aortic neck and the external iliacs, and the internal iliacs were ligated. The circulation fluid was an aqueous glycerol solution with a volume ratio of 40:60 water to glycerol, which has been shown to have a viscosity comparable to that of blood. ${ }^{11}$

The aneurysm and the pump terminals were contained in a transparent cylinder made of acrylic, totally closed except for a hole in the upper edge where a graduated glass tube was attached (Fig. 1 and Fig. 2). This cylinder was

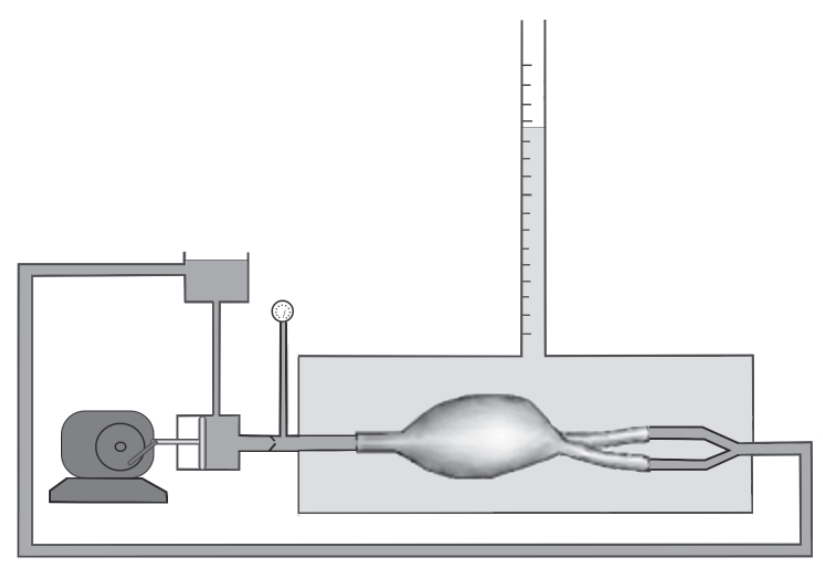

Figure 1 - Schematic representation of the perfusion system.

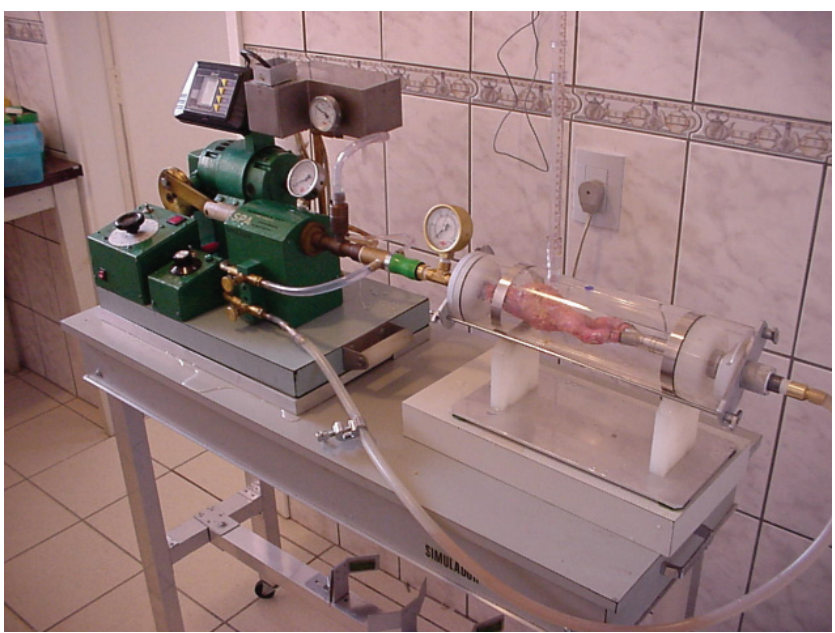

Figure 2 - Aneurysm being submitted to pulsatile perfusion.

Table 1 - Diameters measured in the 5 specimens.

\begin{tabular}{|c|c|c|c|c|c|c|}
\hline Experiment \# & $\begin{array}{l}\text { Proximal neck } \\
\text { diameter }(\mathrm{cm})\end{array}$ & $\begin{array}{l}\text { Proximal neck } \\
\text { length }(\mathrm{cm})\end{array}$ & $\begin{array}{c}\text { Maximum } \\
\text { diameter }(\mathrm{cm})\end{array}$ & $\begin{array}{l}\text { Aneurysm } \\
\text { length }(\mathrm{cm})\end{array}$ & $\begin{array}{l}\text { Right common } \\
\text { iliac artery } \\
\text { diameter }(\mathrm{cm})\end{array}$ & $\begin{array}{l}\text { Left common } \\
\text { iliac artery } \\
\text { diameter }(\mathrm{cm})\end{array}$ \\
\hline 1 & 2.2 & 4.1 & 4.4 & 6.7 & 2.2 & 2.6 \\
\hline 2 & 2.5 & 2.3 & 7.0 & 12 & 1.7 & 1.6 \\
\hline 3 & 2.0 & 4.8 & 4.3 & 5.7 & 2.6 & 2.4 \\
\hline 4 & 2.6 & 2.3 & 4.2 & 5.1 & 1.8 & 1.7 \\
\hline 5 & 2.8 & 1.4 & 6.0 & 6.5 & 1,5 & 1,4 \\
\hline
\end{tabular}


completely filled with saline in order to allow for quantitative measurement of the volume dislodged in each pulsation by observing the rise and fall of the level in the graduated tube and the qualitative behavior (movements) of the aneurysm sac. The variation in the column level at each cycle of the pump was registered and used to calculate the volume dislodged by the aneurysm pulsation, hereafter called V. Thus, pulsatility was measured using volumetric variations rather than changes in diameter.

After recording the pulsatility, each aneurysm was removed from the system, and a bifurcated endograft was implanted. The device used in all cases was the Vanguard II (Boston Scientific, Natick, MA), a nitinol-polyester endograft already discontinued due to failures, but with a short-term behavior similar to other devices made of the same components. ${ }^{12}$

The implant was carried out under direct observation through the sectioned aortic neck, with the non-covered stents over the ostia of the renal arteries. The branches were extended to the common iliacs. For the contralateral limb, passage of the guidewire through the stump in the device was performed in a reverse direction - from the aortic neck to the iliac, with the stump visible through the neck. In four cases, angioscopy was used as an aid to check for correct positioning. In all cases, banding of the aortic neck and common iliacs was performed to avoid any possibility of leakage at those sites. In cases \#1 and \#3, the banding created a neck in the large iliacs.

The space remaining between the device and the mural thrombus was filled with human blood obtained from the blood bank and not usable for transfusion due to excessive storage time. Calcium citrate was added to reverse anticoagulation, and the infusion was made through a cannula inserted between the device and the aortic wall until blood stopped passing to the graft lumen, confirming clotting of the fabric. This was done intentionally to reproduce the clinical situation, where the endograft is surrounded by recent clot and by the mural thrombus, and also to promote sealing of the fabric mesh.

After the implant, the aneurysms were replaced in the simulator in the same position as before, and submitted to perfusion at the same pressures and pulse rates. After these procedures, the aneurysm sac was completely excluded from the circulatory circuit by an endovascular graft.

The variation in the level of the column of saline in the graduated tube was recorded, and the volume dislodged was compared with the previous data for the same specimen. A Wilcoxon Signed-Rank Sum test was performed with the data, assuming 0.05 as $\alpha$.

At the end of each experiment, the aneurysm was opened to check for the correct positioning of the endograft.

\section{RESULTS}

The rise and fall of the saline level for each experiment was constant, indicating that all branches were ligated and no communication occurred between the perfusion media and the liquid around the aneurysm.

The values of $\mathrm{V}$ for each experiment are shown in Table 2. Although there is a tendency toward a reduction in pulsatility after EVAR, no statistical significance was found.

Table 2 - Pulsatility before and after endograft implantation in the 5 aneurysms, represented by volume variation. Variation was not significant at $\mathrm{p}<0.05$.

\begin{tabular}{lcc}
\hline Experiment \# & $\begin{array}{c}\text { Volume variation } \\
\text { before implant }(\mathrm{ml})\end{array}$ & $\begin{array}{c}\text { Volume variation after } \\
\text { implant }(\mathrm{ml})\end{array}$ \\
\hline 1 & 22.2 & 17 \\
2 & 20.9 & 15.7 \\
3 & 17 & 11.8 \\
4 & 9.1 & 4.6 \\
5 & 32,7 & 30.1 \\
\hline
\end{tabular}

Besides the volumetric variation, it was possible to observe that all the aneurysm specimens displayed movements before and after implant of the endovascular graft.

During the post-experimental examination of all of the specimens, the device was found to be well adapted and positioned. A recent thrombus was found around the device, and the mural thrombus was intact (Fig. 3). No evidence of leakage or detachment was encountered. The space between the endograft and the mural thrombus was found to be filled only with the recent clot; no glycerin was present, indicating that the perfusion solution did not pass through the clotted fabric of the graft.

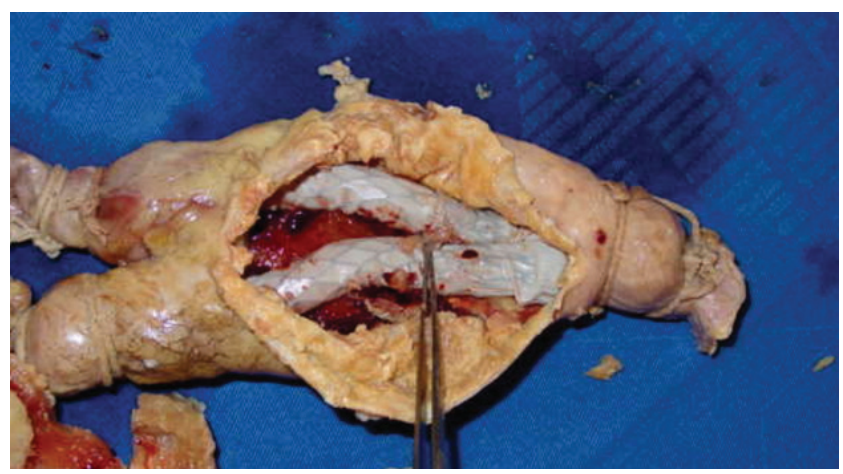

Figure 3 - Inspection of an aneurysm after an experiment, showing mural thrombus and recent clot around the device.

\section{DISCUSSION}

This is the first bench top experiment on EVAR carried out with human aortic aneurysm tissue. The biological soft 
tissue is a heterogeneous material consisting of a complex arrangement of many individual components, each with a unique biomechanical behavior. ${ }^{13} \mathrm{~A}$ striking contrast between human aneurysm tissue and prosthetic tissue or even animal models of aneurysms ${ }^{8,14,15,16}$ should be expected.

We chose to use glycerin as a perfusate instead of blood in order to keep the conditions constant before and after implantation. Blood tends to change viscosity when the machine is stopped, even when anticoagulation is used, and would require the system to be washed between the two phases. In addition, different blood samples do not have the same physical characteristics.

Despite the care taken in pre-clotting of the fabric, a slight type 4 endoleak may have contributed to the results. If this was an important factor, however, we should expect to have found a considerable amount of glycerin in the aneurismal sacs when they were opened after each experiment; however, the aneurysms were found filled only with clotted blood (no glycerin), showing that the fabric clotting was effective.

Unlike in open surgery, endografts for aortic aneurysms are implanted without opening the aneurysm sac. This results in the graft pulsating inside a closed chamber, and a pulsatile wave being transmitted to the aortic wall through the thrombus.

Our work is difficult to compare with other experimental data. First, we found greater aneurysm pulsatility because the aneurysms were tested without the constraint forces normally attached to them. Second, we used human aortic aneurysms, which clearly have different compliance and elasticity from animal aortas and artificial aneurysms sacs made of latex.

Our simulation indicates that transmission of pulsatility from the device to the aneurysm wall does occur. It may vary according to the material used in each particular graft, and should be a concern for manufacturers. ${ }^{2,17,18}$ Pulsatility may theoretically prevent aneurysm shrinking, and even promote enlargement, because the motion can lead to the rupture of wall fibers. However, it does not compromise the success of treatment, since there is no flow inside the sac in the absence of an endoleak, but rather a transmission of a pulsatile wave through static layers of clot. Even in the case of an aneurysm rupture, hemorrhage may not occur.

In conclusion, pulsatility of an aortic aneurysm after EVAR does not always indicate the existence of an endoleak. It may be caused by wave transmission and should not be interpreted as failure of the procedure, provided that the existence of an endoleak is ruled out.

\section{REFERENCES}

1. Lin PH, Bush RL, Katzman JB, Zemel G, Puente OA, Katzen BT et al.Delayed aortic aneurysm enlargement due to endotension after endovascular abdominal aortic aneurysm repair. J Vasc Surg. 2003;38:840-2.

2. Cho JS, Dillavou ED, Rhee RY, Makaroun MS. Late abdominal aortic aneurysm enlargement after endovascular repair with the Excluder device. J Vasc Surg. 2004;39:1236-42.

3. Azevedo FC, Zerati AE, Blasbalg R, Wolosker N, Puech-Leão P. Comparison of ultrasonography, computed tomography and magnetic resonance imaging with intraoperative measurements in the evaluation of abdominal aortic aneurysms. Clinics. 2005;60:21-28.

4. White GH, May J, Petrasek P, Waugh R, Stephen M, Harris J. Endotension: An explanation for continued AAA growth after successful endoluminal repair. J Endovasc Surg. 1999;6:308-15.

5. Gilling-Smith G, Brennan J, Harris P, Bakran A, Gould D, McWillians R. Endotension after endovascular aneurysm repair: definition, classification, and strategies for surveillance and intervenrion. J Endovasc Surg. 1999;6:305-7.

6. Malina M, Länne T, Ivancev K, Lindblad B, Brunkwall J. Reduced pulsatile wall motion of abdominal aortic aneurysms after endovascular repair. J Vasc Surg. 1998;27:624-31.

7. Schurink GWH, Aarts NJM, Malina M, van Bockel JH. Pulsatile wall motion and blood pressure in aneurysms with open and thrombosed endoleaks - comparison of a wall track system and M-mode ultrasound scanning: An in vitro and animal study. J Vasc Surg. 2000;32:795-803.

8. Mehta M, Veith FJ, Ohki T, Lipsitz EC, Cayne NS, Darling III RC. Significance of endotension, endoleak, and aneurysm pulsatility after endovascular repair. J Vasc Surg. 2003;37:842-6.

9. Greenberg R, Green R. A clinical perspective on the management of endoleaks after abdominal aortic endovascular aneurysm repair. J Vasc Surg. 2000;31:836-7.
10. Veith FJ, Baum RA, Ohki T, Amor M, Adiseshiah M, Blankensteijn JD et al. Nature and significance of endoleaks and endotension: Summary of opinions expressed at an international conference. J Vasc Surg. 2002;35:1029-35.

11. Fisher RK, How TV, Toonder IM, Hoedt MT, Brennan JA, Gilling-Smith GL et al. Harnessing haemodinamic forces for the suppression of anastomotic intimal hyperplasia: the rationale for precuffed grafts. Eur J Vasc Endovasc Surg. 2001;21:520-8.

12. Rutherford RB, Krupski WC. Current status of open versus endovascular stent-graft repair of abdominal aortic aneurysm. J Vasc Surg. 2004;39:1129-1139.

13. Raghavan ML, Webster MW, Vorp DA. Ex vivo biomechanical behavior of abdominal aortic aneurysm: assessment using a new mathematical model. Ann Biomed Eng. 1996;24:573-82.

14. Criado E, Marston WA, Woosley JT, Ligush J, Chuter TA, Baird C. An aortic aneurysm model for the evaluation of endovascular exclusion prostheses. J Vasc Surg. 1995;22:306-15.

15. Sanchez LA, Faries PL, Marin ML, Ohki T, Parsons RE, Marty B. Chronic intraaneurysmal pressure measurement: an experimental method for evaluating the effectiveness of endovascular aortic aneurysm exclusion. J Vasc Surg. 1997;26:222-30.

16. Schurink GWH, Aarts NJM, van Baalen JM, Chuter TAM, Kool LJS, van Bockel JH. Endoleakage after stent-graft treatment of abdominal aneurysm: Implications on pressure and imaging-an in vitro study. J Vasc Surg. 1998;28:234-41.

17. Bertges DJ, Chow K, Wyres MC, Landsittel D, Frydrych AV, Stavropoulos W. Abdominal aortic aneurysm size regression after endovascular repair is endograft dependent. J Vasc Surg. 2003;37:716-23.

18. Ouriel K, Clair DG, Greenberg RK, Lyden SP, O'Hara PJ, Sarac TP. Endovascular repair of abdominal aortic aneurysms: device-specific outcome. J Vasc Surg. 2003;37:991-8. 